\title{
Quantitative Bestimmung der Bestandtheile des Oxyhämoglobins des Pferdes.
}

Von

D. L̦awrow.

(Aus dem physiol.-chem. Laboratorium der St. Petersburger militär-ärztl. Akademie.)

(Der Redaction zugegangen am 24. Oktober 1898.)

Die Bestandtheile des Oxyhämoglobins sind im Allgemeinen wenig untersucht und die Ansichten über dieselben verschieden, denn einige Autoren glauben, dass das Oxyhämoglobin nur aus zwei Bestandtheilen besteht - Eiweissstoff und Farbstoff; andere, wie (Lehmann, ${ }^{1}$ F. Hoppe-Seyler, ${ }^{2}$ ) Preyer, ${ }^{3}$ ) Schulz, $\left.{ }^{4}\right)$ nehmen im Oxyhämoglobin ausser den beiden genannten Bestandtheilen noch andere Substanzen an.

Ebenso verschieden sind die Meinungen über den chemischen Charakter des Eiweissstoffes im 0xyhämoglobin. So hält Preyer die Eiweisssubstanz des Oxyhämoglobins, das «Globin. für ein Albumin besonderer Art; F. Hoppe-Seyler für ein Globulin, und Schulz für ein Histon.

Die Methoden, welche zur Zerlegung des Oxyhämoglobins in seine Bestandtheile angewandt wurden, waren folgende: F. Hoppe-Seyler zerlegte das Oxyhämoglobin durch Kochen seiner wässerigen Lösung, wobei die Proteinsubstanz des 0xy-

1) Lehrbuch d. physiol. Chemie, 1853 , S. $364-369$.

2) Medicin.-chem. Untersuch. Th. III, \& 18, Th. IV, § 26.

3) Blutkrystalle, 1871, S. 164 u. folg.

4) Diese Zeitschrift, Bd. XXIV, S. 449-481, 1898. 
hämoglobins in Flocken ausfällt. Preyer ${ }^{1}$ ) zersetzte das $0 x y-$ hämoglobin, indem er auf eine wässerige Lösung desselben durch Essigsäure in Gegenwart von Aether einwirkt; dabei bilden sich beim Stehen des Gemisches zwei Schichten, eine untenstehende, farblose, die Proteinsubstanz des Oxyhämoglobins in Lösung enthaltende, und eine obenstehende, gefärbte, welche alle anderen Bestandtheile des Oxyhämoglobins aufgenommen hat.

A. Danilewsky führte die Spaltung herbei durch kurz dauerndes Kochen einer wässerigen, mit einem gleichen Volumen 95\% igen Alkohols gemischten Lösung des Oxyhämoglobins. Der abgespaltene Eiweissstoff des Oxyhämoglobins löst sich in der heissen 40-45\% igen alkoholischen Lösung, aus der er beim Abkühlen ausfällt. Um diese Eiweisssubstanz in reinem Zustande darzustellen, wird die erhaltene alkoholische Lösung heiss filtrirt; das Filtrat scheidet beim Abkühlen den Eiweissstoff als flockigen Niederschlag ab, der mit Fliesspapier abgepresst, nochmals in $45 \%$ igem heissen Alkohol gelöst und durch Abkühlen seines Lösungsmittels von Neuem ausgeschieden wird. Dieses Reinigungsverfahren kann mehrere Male wiederholt werden. Ist die alkoholische Lösung der Eiweisssubstanz gelb gefärbt, so wird sie durch Thierkohle entfärbt.

Schulzi) spaltet das Oxyhämoglobin in der Weise, dass er der wässerigen Lösung des Oxyhämoglobins verdünnte Salzsäure so lange hinzufügt, bis der zuerst entstandene Niederschlag wieder verschwindet. Die so erhaltene saure Lösung wird mit $1 / 5$ Volumen $80 \%$ igen Alkohols und $1 / 2$ Volumen Aether unter sorgfältigem Umrühren gemischt. Das Hämatin geht in die ätherische Lösung, der Eiweissstoff und andere Bestandtheile bleiben in der wässerig-alkoholischen Lösung.

Für meine eigenen, auf die Zusammensetzung des Oxyhämoglobins bezüglichen Untersuchungen benutzte ich das Oxyhämoglobin des Pferdes. Die Darstellung des Oxyhämoglobins gestaltete sich folgendermassen: das frisch gelassene Blut wurde mit Ammoniumoxalat gemischt $(1 \mathrm{gr}$. dieses Salzes

1) 1. c. 
auf je 1 Liter Blut) und bei der Temperatur von etwa $0^{\circ} \mathrm{C}$. stehen gelassen. Nach 24 Stunden wurde die Plasma- und die Leucocytenschicht vom dicken Blutkörperchenbrei abgegossen. Darauf wurde der letztere mit 2 Volumen destillirten Wassers von Zimmertemperatur und etwas Aether gut gemischt und die Mischung zuerst bei $15-20^{\circ} \mathrm{C}$., endlich bei $0^{\circ} \mathrm{C}$. etwa 24 Stunden gehalten. Jetzt wurde der in Lösung gegangene Blutfarbstoff durch Fliesspapier bei etwa $0^{0}$. filtrirt und dem Filtrate 1/^ Volumen stark abgekühlten 95\% igen Alkohols allmählich unter sorgfältigem Umrühren hinzugefügt. Die alkoholische Mischung war nach 24-48 stündigem Stehen bei $-12^{\circ}$ bis $-15^{\circ} \mathrm{C}$. zum krystallinischen Brei erstarrt. Der bei $-10^{\circ}$ bis $-15^{\circ} \mathrm{C}$. abgetrennte krystallinische Niederschlag wurde zwischen Fliesspapier sorgfältig abgepresst und zweimal auf angegebene Weise umkrystallisirt.

Das auf diese Weise dargestellte Oxyhämoglobin enthielt $0,469 \%$ Eisen.

Zur quantitativen Bestimmung des Eisens wurde das gelöste und filtrirte Oxyhämoglobin zuerst bei $100^{\circ}$, dann bei $110-115^{\circ}$ C. getrocknet und mit 15 Theilen Salpetergemisch verbrannt. Das Eisen wurde als Eisenoxyd bestimmt.

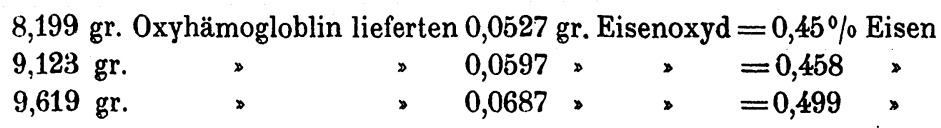

Demnach betrug die Mittelgrösse des Eisengehalts die oben angegebene Zahl von $0,469 \%$.

Zur Spaltung des gewonnenen Oxyhämoglobins versetzte ich die wässerige Lösung desselben mit einer Alkohol, Aether und Schwefelsäure enthaltenden Mischung und zwar kamen auf je $100 \mathrm{ccm}$. Lösung des Oxyhämoglobins $500 \mathrm{ccm}$. 75\% igen Alkohols + $200 \mathrm{ccm}$. Aether; der Gehalt der Mischung $(800 \mathrm{ccm}$.) an Schwefelsäure beträgt $0,025 \%$.

Das Zusammenmischen wird sehr allmählich unter sorgfältigem Umrühren durchgeführt. Dabei fällt die Proteinsubstanz des Oxyhämoglobins in Flocken aus; alle anderen Bestandtheile bleiben in der alkohol-ätherischen Lösung. Kocht man die abgetrennte alkohol-ätherische Lösung bis zur vollkommenen Ver- 
jagung des Aethers und Alkohols, so fällt das Hamatin ganz aus. In dem wässerigen Filtrate vom Hämatin ist keine Proteinsubstanz mehr nachzuweisen, sodass man annehmen muss, dass die Eiweisssubstanz des Oxyhämoglobins bei der angegebenen Spaltung vollkommen ausgeschieden wird.

Um die Quantität des abgespaltenen Hämatins festzustellen, wurde das alkohol-ätherische Filtrat vom Proteinniederschlage, sammt den ersten gefärbten alkohol-ätherischen Waschflüssigkeiten bis zur vollkommenen Vertreibung des Alkohols und Aethers gekocht. Dabei fällt das Hämatin vollkommen aus. Das abgeschiedene Hämatin wurde auf einem getrockneten und gewogenen Filter zuerst mit heissem Wasser bis zur vollkommenen Entfernung der Schwefelsäure, darauf mit Alkohol und Aether durchgewaschen und bei $110-115^{\circ} \mathrm{C}$. bis zum constanten Gewichte getrocknet.

Zur quantitativen Bestimmung der Menge der Proteinsubstanz des Oxyhämoglobins wurde eine Oxyhämoglobinlösung von bekanntem Gehalte nach dem oben geschilderten Verfahren zerlegt, der abgeschiedene Proteinniederschlag auf einem Filter von bekanntem Gewicht gesammelt, mit einem Gemisch aus 2 Volumen 60\% igen Alkohols und 1 Volumen Aether bis zur Entfernung der mechanisch beigemengten Schwefelsäure ausgewaschen und bei $110-115^{\circ} \mathrm{C}$. bis zum constanten Gewicht getrocknet.

Die Analysen gaben die folgenden Resultate:

$100 \mathrm{ccm}$. einer $2,782 \%$ igen $0 x y$ hämoglobinlösung lieferten $2,761 \mathrm{gr}$. $=99,23 \%$ Niederschlag.

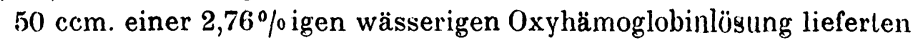
1,3731 gr. $=99,50 \%$ Niederschlag und 0,0536 gr. $=3,88 \%$ Hämatin.

$50 \mathrm{ccm}$. einer $2,76 \%$ igen wässerigen Oxyhämoglobinlösung lieferten 1,3736 gr. $=99,54^{\circ} \%$ Niederschlag.

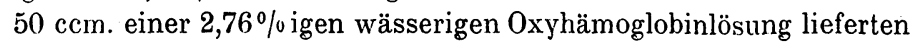
1,3701 gr. $=99,28 \%$ Niederschlag und 0,0551 gr. $=3,99 \%$ Hämatin.

$100 \mathrm{ccm}$. einer $2,776 \%$ igen wässerigen Oxyhämoglobinlösung gaben 0,1046 gr. $=3,77 \%$ Hämatin.

Als Mittelwerthe für die Menge des aus dem Oxyhämoglobin abgespaltenen Proteins fanden sich demnach 99,39\% und für das entstandene Hämatin 3,88\%. 
Diese Zahlen bedürfen jedoch noch der Correctur, da von dem Proteine Schwefelsäure in gebundener Form zurückgehalten wird. Ićh bestimmte daher die Schwefelsäure verschiedener Präparate des Proteins nach den üblichen $\mathrm{Me}$ thoden. Die Resultate sind in nachstehender Tabelle zusammengestellt:

\begin{tabular}{|c|c|c|c|c|}
\hline Nr. des Präparates . . . . . & I & II & III & IV \\
\hline Menge des veraschten Proteins. . & 5,020 & 3,711 & 2,7467 & 1,3701 \\
\hline $\begin{array}{l}\text { Menge des Oxyhämoglobins, welche } \\
\text { dem veraschten Protein ent- } \\
\text { spricht } . . \\
\end{array}$ & 5,051 & 3,733 & 2,76 & 1.38 \\
\hline Gewicht des Baryumsulfats . . & 0,836 & 0,619 & 0,4153 & 0,2265 \\
\hline $\begin{array}{l}\text { Menge der gebundenen Schwefel- } \\
\text { säure in } \% \text {. . . . . . }\end{array}$ & 5,26 & 4,86 & 4,56 & 5,21 \\
\hline
\end{tabular}

Von den in der Tabelle aufgeführten Werthen für Schwefelsäure sind. bereits abgezogen die Werthe, die der im Proteinmolekül gebundene Schwefel liefern muss. Da der gesammte Schwefel des Oxyhämoglobins nach meinen Erfahrungen in das abgespaltene Protein übergeht und das von mir benutzte Oxyhämoglobin 0,65\% Schwefel enthielt, so habe ich die der genannten Zahl entsprechende Schwefelsäure in Abzug gebracht.

Setze ich jetzt die gefundene Schwefelsäure in Beziehung zu der gefundenen Menge des Proteins, dann lässt sich leicht die Menge des schwefelsäurefreien Proteins berechnen. Es ergibt sich nämlich, wenn ich die gesuchte von Schwefelsäure freie Substanz mit X bezeichne, die Gleichung $X+\frac{4,97}{100} X=99,39$ $\mathrm{X}=94,68$.

Da jedoch das Protein noch Eisen enthielt, das wahrscheinlich aus Hämatin stammt, welches von dem ausfallenden Proteid mit niedergerissen wird, muss die Menge des beigemischten Hämatins ebenfalls von der zuletzt gefundenen Zahl 
in Abzug gebracht werden. Nach der in der Fussnote*) ausgeführten Rechnung müsste nun eigentlich das von mir angewandte Oxyhämoglobin $4,47 \%$ Hämatin bei der Spaltung liefern. In Wirklichkeit fand ich jedoch nur $3,88 \%$. Es müssen demnach $4,47-3,88 \%=0,59 \%$ von dem Proteid mitgerissen sein. Unter Berücksichtigung dieser letzten Zahlen ergibt sich also, dass das Oxyhämoglobin bei seiner Spaltung 94,09\% Eiweissstoff, $4,47 \%$ Hämatin und 1,44\% andere Bestandtheile geliefert hat.

Nach Schul ${ }^{1}$ ) beträgt der Gehalt des Oxyhämoglobins an Eiweissstoff ( Globin») 86,5\%, an Hämatin $4,2 \%$ und an anderen Bestandtheilen 9,3\%. (N.B. Der Autor selbst hat darauf hingewiesen, dass die Proteinsubstanzen des Oxyhämoglobins bei seiner Bestimmung nicht ganz vollkommen abgetrennt sind.)

Die nach meinem Verfahren dargestellte Proteinsubstanz des Oxyhämoglobins gibt alle Farbenreactionen, die den echten Eiweissstoffen eigenthümlich sind, aber schwächer als zum Beispiel das Eieralbumin. Sie enthält leicht beim Kochen mit Aetzalkali abtrennbaren Schwefel, jedoch in geringer Menge.

Ihre Fähigkeit zur Dialyse ist sehr gering. Nachdem sie mit kaltem Wasser vollkommen ausgewaschen ist, ist sie in Wasser von Zimmertemperatur fast unlöslich. Ziemlich leicht ist sie in verdünnten Mineralsäuren und sehr leicht in

*) Nach den Untersuchungen von F. Hoppe-Seyler ${ }^{1}$ ) enthält das Hämatin 8,82\% Eisen. Nach Nencki und Si eber ${ }^{2}$ ) beträgt der Gehalt des Hämatins an Eisen 9,46\%. Nach zweien von mir ausgeführten Analysen beträgt der Gehalt des Hämatins an Eisen 10,50\%, sodass das von mir benutzte Oxyhämoglobin $\frac{0,469}{10,50} \cdot 100=4,47 \%$ Hämatin zu enthalten hat.

Die Analysen gaben Folgendes:

0,6292 gr. Hämatin lieferten $0,095 \mathrm{gr}$. Eisenoxyd $=10,56 \%$ Eisen. 0,6427 » \ 0,0958 » $=10,43 \%$ »

1) l. c.

2) Arch. f. exper. Path. u. Pharm. Bd. XVIII, Jahrg. 1884, S. 401. Ber. d. d. chem. Ges. Bd. XVII, Jahrg. 1884, S. 2267, Bd. XVIII, Jahrg. 1885, S. 392. 
Aetzalkali löslich. Sie lässt sich aus ihren sauren Lösungen durch Natriumcarbonat oder Ammoniak ausscheiden. Die dabei entstehenden Niederschläge sind in einem nicht zu grossen Ueberschusse der genannten Reagentien, sogar beim Erwärmen und Kochen der Lösung unlöslich. Mit Salpetersäure geben ihre sauren Lösungen Niederschläge nur bei einigem Ueberschusse der Säure. Dieselben lösen sich beim Erwärmen und Kochen. Die sauren Lösungen der Proteinsubstanz geben mit 1 Volumen starken Alkohols Niederschläge, die beim Erwärmen und Kochen verschwinden und beim Erkalten wieder erscheinen. Eine kleine Menge von Kochsalz erzeugt in ihren sauren Lösungen starke Niederschläge. Diese Fällungsreactionen sind so charakteristisch, dass die Proteinsubstanz des Oxyhämoglobins als eine besondere Proteinsubstanz anzusehen ist.

Die vorläufige kurze Untersuchung des Gemenges der Stoffe, welche ausser Eiweiss und Hämatin im Oxyhämoglobin vorhanden sind, hat gezeigt, dass dasselbe zum Theil von Fettsäuren gebildet wird, von denen einige im Wasser löslich sind, andere nicht. Einige der Fettsäuren sind mit Wasserdämpfen flüchtig, andere nicht. Beim Erhitzen des Gemenges mit Aetznatron entwickelt sich Ammoniak.

Schliesslich kann ich nicht umhin, Herrn Prof. A. Danilewsky meinen besten Dank auszusprechen für das freundliche Interesse an meiner Arbeit. 